\title{
Analisa Persediaan Bahan Baku Mengunakan Metode EOQ (Economy Order Quantity) di CV. Alfa Nafis
}

\author{
Sofiyanurriyanti \\ Program Studi Teknik Industri, Sekolah Tinggi Teknik Qomaruddin Gresik \\ sofiyanurriyanti20@gmail.com
}

\begin{abstract}
ABSTRAK
Persaingan yang semakin ketat antar perusahaan mendorong setiap perusahaan untuk menetapkan pengendalian terhadap persediaan bahan baku secara tepat guna untuk mencapai tujuan perusahaan yang diinginkan, Salah satunya dengan cara mengetahui persediaan bahan baku pembantu dan menggunakan metode Economy Order Quantity guna untuk memaksimalkan kinerja pada setiap bagiannya. Pengumpulan dan menggunakan wawancara dan dokumentasi. Analisis data yang digunakan dalam penelitian ini adalah Economy Order Quantity. Penelitian ini bertujuan untuk menentukkan pengendalian persediaan bahan baku dengan menggunakan metode Economy Order Quantity di CV. Alfa Nafis. Data permintaan baja ringan pada tahun 2016 sebesar 93 unit. Dimana biaya persediaan terdiri dari biaya pemesanan meliputi biaya pengangkutan dan bongkar muat, biaya adminitrasi, biaya telepon, sedangkan biaya penyimpanan terdiri biaya listrik gudang dan biaya pajak. Untuk biaya pemesanan setiap kali pesan sebesar Rp 183.333,00. Perhitungan pada EOQ dapat menyimpulkan bahwa pembelian bahan baku baja ringan yang ekonomis adalah $8.124 \mathrm{~m}^{2}$ dengan frekuensi 4 kali pemesanan dalam satu minggu. Maka sebaiknya CV Alfa Nafis sebaiknya menerapka metode Economy Order Quantity didalam menentukan kuantitas pembelian bahan baku pembantu secara optimal sehingga dapat meminimalkan total biaya yang akan dikeluarkan oleh perusahaan setiap tahunnya.

Kata Kunci: Economy Order Quantity, Biaya Persediaan, Biaya Pemesanan.
\end{abstract}

\section{Forecasting Analysis and Raw Material Supplies Using EOQ Method (Economy Order Quantity) in CV. Alfa Nafis}

\section{ABSTRACT}

Increasingly intense competition between companies encourages each company to establish control of raw material inventory in an appropriate manner to achieve the desired corporate objectives, one of them by knowing the supply of raw materials and using the method of Economy Order Quantity in order to maximize performance in each part. Collecting and using interviews and documentation. Data analysis used in this research is Economy Order Quantity. This study aims to establish raw material inventory control using Economy Order Quantity method in CV. Alfa Nafis. Data of light steel demand in 2016 amounted to 93 units. Where the cost of inventory consists of the cost of ordering include the cost of transportation and loading and unloading, administrative costs, telephone costs, while the storage costs consist of warehouse electricity costs and tax costs. For booking fee every time the message is Rp 183,333,00. Calculations on EOQ can conclude that the purchase of lightweight, economically feasible steel is $8,124 \mathrm{~m}^{\wedge}$ 2 with a frequency of 4 orders in a week. Then CV Alfa Nafis should preferably apply the Economy Order Quantity method in determining the quantity of purchase of raw material auxiliary optimally so as to minimize the total cost to be issued by the company every year.

Keywords: Economy Order Quantity, Inventory Cost, Booking Cost. 


\section{PENDAHULUAN}

Perkembangan perekonomian di Negara Indonesia saat ini berkembang dan tumbuh dengan pesat, seiring dengan persaingan antar perusahaan semakin ketat. Persaingan yang semakin ketat antar perusahaan mendorong setiap perusahaan untuk menetapkan pengendalian terhadap persediaan bahan baku secara tepat guna untuk mencapai tujuan perusahaan yang diinginkan, Persedian merupakan hal terpenting dalam suatu perusahaan dan mempunyai pengaruh penting pada fungsi bisnis terutama fungsi operasional pemasaran. Setiap perusahaan baik itu perusahaan jasa maupun perusahaan manufaktur mempunyai tujuan yang sama yaitu memperoleh keuntungan atau laba yang diharapkan. metode Economic Order Quantity (EOQ) didalam pengendalian persediaan bahan baku, karena metode Economic Order Quantity (EOQ) merupakan metode yang sesuai atau tepat untuk diterapkan didalam pengendalian persediaan bahan baku didalam menentukan kualitas dan kuantitas. CV. Alfa Nafis merupakan salah satu perusahaan industri yang berada di Unjungpangkah Gresik salah satu hasil produksi utamanya adalah baja ringan. Perusahaan industri ini memerlukan pengendalian persediaan bahan dengan metode Economic Order Quantity (EOQ) didalam melakukan pemesanan atau pembelian bahan baku. Pengendalian persediaan bahan baku merupakan tindakan sangat penting yang harus dilakukan oleh

pihak perusahaan didalam menghitung berapa jumlah optimal tingkat persediaan yang diharuskan, serta kapan saatnya mulai mengadakan pembelian atau pemesanan kembali. Menurut pendapat Schroeder (2000) yang mengatakan bahwa definisi persediaan atau inventory adalah stock bahan yang digunakan untuk memudahkan produksi atau untuk memuaskan permintaan pelanggan. Sedangkan menurut Kusuma (2009) mengatakan persediaan didefinisikan sebagai barang yang disimpan untuk digunakan atau dijual pada periode mendatang. CV. Alfa Nafis merupakan salah satu perusahaan industri yang memerlukan pengendalian persediaan bahan dengan metode Economic Order Quantity didalam melakukan pemesanan atau pembelian bahan baku. Pengendalian persediaan merupakan tindakan sangat penting yang harus dilakukan oleh pihak perusahaan didalam menghitung berapa jumlah optimal tingkat persediaan yang diharuskan, serta kapan saatnya mulai mengadakan pembelian atau pemesanan kembali. Bila terlalu sedikit persediaan akan mengakibatkan produksi terhambat karena bahan baku tidak ada, sedangkan bahan baku terlalu banyak akan mengakibatkan beban biaya penyimpanan meningkat dan resiko kehilangan atau kerusakan meningkat karena semakin lamanya penyimpanan bahan baku tersebut terdapat jumlah selisih permintaan teras baja ringan pada setiap bulannya. Oleh karena itu, berdasarkan latar belakang diatas maka penelitian ini diperusahaan $\mathrm{CV}$. Alfa Nafis dapat menentukan persedian bahan baku dengan mengunakan metode Economic Order Quantity (EOQ).

\section{METODE PENELITIAN}

Pada metode penelitian ini yang digunakan dalam penelitian ini selama periode 1 tahun pada tahun 2016. CV. Alfa Nafis yang berada di wilayah Jawa Timur, terletak di Desa 
Glatik RT/RW, 06/02 Kecamatan Ujungpangkah Kabupaten Gresik yang memproduksi bahan baku baja ringan. Jenis penelitian ini terdiri dari biaya pemesanan, biaya penyimpanan, total biaya pemesanan, dan penyimpanan bahan baku pembantu. Namun penelitian ini fokus mengunakan metode Economy Order Quantity yang terdiri dari kuantitas pembelian bahan baku pembantu, frekuensi pembelian bahan baku pembantu, biaya pemesanan bahan baku pembantu, biaya penyimpanan bahan baku pembantu, total biaya bahan baku pembantu, persediaan penyelamat, titik pemesanan kembali. Metode EOQ ini digunakan untuk kuantitas pesanan persediaan yang meminimkan biaya langsung penyimpanan persediaan. Economic Order Quantity adalah salah satu metode yang digunakan dalam penentuan jumlah kuantitas pemesanaan yang optimal (Syamsuddin, 2011).

Asumsi Model EOQ (Handoko, 1999) meliputi permintaan akan produk adalah kostan, seragam dan diketahui, Harga per unit adalah konstan, Biaya per unit per tahun $(\mathrm{H})$ adalah konstan. Biaya pemesanan per pesan (S) adalah konstan. Waktu antara pemesan dilakuakan dan barang-barang diterima adalah konstan.

Asumsi yang digunakan metode $E O Q$ :

$$
E O Q=\sqrt{\frac{2 D S}{H}}
$$

Dimana $D$ adalah penggunaan atau permintaan yang diperkirakan per periode waktu, $S$ adalah biaya pemesanan (persiapam pesanan dan mesin) per pesan, $\mathrm{H}$ adalah biaya penyimpanan per unit.

\section{Frekuensi pemesanan bahan baku:}

$$
\mathbf{F}=\frac{D}{Q_{*}}
$$

Dimana $F$ adalah Frekuensi pemesanan yang optimal, $Q$ adalah jumlah pemesanan optimal, D adalah permintaan yang diperkirakan per periode waktu.

\section{Total biaya persediaan bahan baku:}

Persediaan (inventory) adalah barang atau bahan yang merupakan salah satu kekayaan organisasi yang disimpan dalam antisipasinya terhadap pemenuhan permintaan (Handoko, 2011:333).

$\mathrm{TCl}=\left\{\frac{D}{Q^{*}} s\right\}+\left\{\frac{Q *}{2} H\right\}$

Dimana TIC adalah Totoal biaya pesan + total biaya simpan., $Q$ adalah Jumlah optimal baja ringan perpesan (gelondongan), $\mathrm{H}$ adalah Biaya penyimpanan Pertahun, $S$ adalah Biaya pemesan sekali pesan (Rp).

\section{Persediaan pengaman (Safety stock)}

Persediaan yang dilakuklan untuk mengantisipasi adanya ketidakpastian permintaan dan kekurangan bahan baku (Ristono, 2009).

$\mathrm{SS}=\mathrm{Z} \times \mathrm{SD}$

Dimana SS adalah persediaan pengaman, $X$ adalah nilai dengan penyimpanan sebesar $55 \%$ yang dibuat pada tabel Z (kurva normal).

$\mathrm{SD}=\sqrt{\frac{\sum\left(x-X^{-}\right.}{n}}$

Dimana SD adalah standart deviasi, $\mathrm{X}$ adalah pemakaian bahan baku 
sebenarnya, $\mathrm{X}$ bar adalah perkiraan penggunaan bahan baku, $\mathrm{N}$ adalah jumlah data.

\section{Titik Pemesanan Ulang atau $\boldsymbol{R e}$ Order Point}

Titik pemesanan kembali atau $R e$ Order Point adalah suatu titik dimana harus dilakukannya pemesanan kembali (Heizer, 2008:75)

ROP : $(d \times L)+S S$

Dimana ROP adalah titik pemesanan ulang, d adalah titik kebutuhan perunit waktu, SS adalah persediaan pengaman dan $L$ adalah Lead time. Lead time adalah jarak waktu tunggu dari awal pemesanan sampai saat datangnya bahan mentah yang dipesan dan siap untuk digunakan dalam proses produksi (Sofyan, 2013:58).

\section{HASIL DAN PEMBAHASAN}

Berikut ini merupakan data permintaan baja ringan dalam 1 tahun pada tahun 2016 di CV. Alfa Nafis. Terdiri dari biaya pemesanan, biaya penyimpanan.

Tabel 1. Data permintaan baja ringan

\begin{tabular}{llll}
\hline No. & Bulan & $\begin{array}{c}\text { Permin- } \\
\text { taan }\end{array}$ & Satuan \\
\hline 1. & Jan & 8 & Unit \\
2. & Feb & 5 & Unit \\
3. & Maret & 7 & Unit \\
4. & April & 11 & Unit \\
5. & Mei & 4 & Unit \\
6. & Juni & 5 & Unit \\
7. & Juli & 5 & Unit \\
8. & Aug & 9 & Unit \\
9. & Sept & 9 & Unit \\
10. & Okt & 10 & Unit \\
11. & Nov & 10 & Unit \\
12. & Des & 10 & Unit \\
& Jumlah & 93 & Unit \\
\hline
\end{tabular}

Sumber: CV. Alfa Nafis, 2016
Tabel 2. Biaya pemesanan CV. Alfa

Nafis

\begin{tabular}{clc}
\hline No. & \multicolumn{1}{c}{ Jenis biaya } & Jumlah biaya \\
\hline 1. & Biaya & Rp. 1.000 .000 \\
& $\begin{array}{l}\text { Pengangkutan Dan } \\
\text { Bongkar Muat }\end{array}$ \\
2. & Biaya Admidrasi & Rp. 700.000 \\
3. & Biaya Telepon & Rp. 500.000 \\
& Jumlah & Rp 2.200.000 \\
\hline \multicolumn{2}{l}{ Sumber: Data primer diolah, 2016}
\end{tabular}

Tabel 3. Rincian Biaya Penyimpanan

\begin{tabular}{clc}
\hline No. & \multicolumn{1}{c}{ Jenis biaya } & Jumlah biaya \\
\hline 1. & Biaya listrik gudang & Rp. 1.500 .000 \\
2. & Biaya pajak & Rp. 2.500 .000 \\
& Jumlah biaya & Rp. 4.000 .000 \\
\hline
\end{tabular}

Sumber: Data primer diolah, 2016

\section{Frekuensi Pemesanan}

Total kebutuan baja ringan:

$$
\text { (D) } \begin{aligned}
& =\frac{\text { Total Kebutuan }}{\text { Frekuensi Pemesanan }} \\
& =\frac{93}{12}=7.75 \text { unit. }
\end{aligned}
$$

Jumlah pembelian bahan baku di CV. Alfa Nafis dalam 1 kali pemesanan sebesar 7,75 unit

$$
\begin{aligned}
& \text { Biaya pemesanan setiap kali } \\
& \mathrm{S}=\frac{\text { Total Biaya Pesan }}{\text { Frekuensi Pemesanan }} \\
& =\frac{\mathbf{2 . 2 0 0 . 0 0 0}}{\mathbf{1 2}}=\mathrm{Rp} .183 .333
\end{aligned}
$$

\section{Biaya penyimpanan persatuan bahan baku (h)}

$$
\begin{aligned}
\mathrm{H} & =\frac{\text { Total Biaya Pesan }}{\text { Total Kebutuan Bahan Baku }} \\
& =\frac{4.000 .000}{93}=43.010 \\
& =\text { Rp. } 43.000
\end{aligned}
$$

Jadi biaya penyimpanan persatuan bahan baku setiap satu kali pesan sebesar Rp.43.000. 


\section{Metode EOQ}

Pembelian bahan baku yang ekonomis ini didasarkan pada:

Total kebutuan bahan baku

(D) $=7.75$ unit.

Biaya pemesanan sekali pesan

(S) = Rp. 183.333

Biaya simpan per unit

$(\mathrm{H}) \quad=$ Rp. 43/unit

Maka setelah diketahui hal seperti diatas, besarnya pembelian bahan baku yang ekonomis mengunakan metode EOQ adalah sebagai berikut:

$\mathrm{EOQ}=\sqrt{\frac{2 D S}{H}}$

$E O Q=\sqrt{\frac{2 \times 7.75 \times 183.333}{43}}$

$E O Q=\sqrt{66.085 .151}$

$E O Q=\sqrt{66}=8.124$ unit.

Jadi jumlah pembelian yang ekonomis dengan mengunakan metode EOQ adalah sebesar 8.124 unit/satu kali pesan

\section{Frekuensi pemesanan bahan baku}

Dengan mengunakan metode EOQ dapat dihitung jumlah frekuensi pemesanan dalam satu tahun atau sering frekuensi pembelian dapat dihitung sebagai berikut:

$\mathrm{F}=\frac{\mathrm{D}}{Q *}$

$F \frac{7.75}{8.124}$

$F=0.000953=0.1$

\section{Total biaya persedian}

Agar dapat menghitung biaya persediaan maka terlebih dahulu diketahui.

Total kebutuan baja ringan $(D)=7.75$ unit.

Biaya pemesanan sekali pesan

(S) = Rp. 183.333 per pesan

Biaya simpan per unit

$(\mathrm{H})=$ Rp. 43/unit.

Pembelian bahan baku ekonomis $\left(Q^{*}\right)$

$=8.124$ unit
$\mathrm{TIC}=\left\{\frac{7.75}{8.124} \times 183.33\right\}+\left\{\frac{8.124}{2} \times 43\right\}$

$\mathrm{TIC}=174.893+174.666$

$\mathrm{TIC}=\mathrm{Rp} .349 .559$

\section{Penentuan persedian pengaman}

Persedian pengaman ini sering disebut dengan istilah Safety Stock didalam perusahaan yang besar, safety stock sangat diperlukan guna menunjang kelancaran proses produksi yang berlansung. seperti halnya menghindari kekurangan bahan baku yang akan mengakibatkan terhenti dan karyawan tidak berkerja. Hal ini sangat merugikan bagi pihak perusahaan dalam memperhitungkan persediaan pengaman digunakan metode statistika dengan membandingkan rata-rata bahan baku dengan pemakaian bahan baku yang sesunggunya kemudian dicari penyimpangannya. pengaman yang harus disediakan oleh perusahaan adalah dengan mengunakan rumus standart Deviasi sebagai berikut:

Berdasarkan Tabel 4 untuk menentukan persedian pengaman yang harus disediakan oleh perusahaan adalah dengan mengunakan rumus standart Deviasi sebagai berikut:

Tabel 4. Perhitungan standar deviasi

\begin{tabular}{llccll}
\hline No. & Bulan & $\begin{array}{c}\text { Permin- } \\
\text { taan }\end{array}$ & $\mathbf{x}$ & $\overline{\mathbf{x}}-\mathbf{x}$ & $-(\mathbf{x}-\mathbf{x})^{2-}$ \\
\hline 1. & Jan & 8 & 7.75 & 0.25 & 0.0625 \\
2. & Feb & 5 & 7.75 & -2.75 & 7.5625 \\
3. & Maret & 7 & 7.75 & -0.75 & 0.5625 \\
4. & April & 11 & 7.75 & 3.25 & 10.562 \\
5. & Mei & 4 & 7.75 & -3.75 & 14.062 \\
6. & Juni & 5 & 7.75 & -275 & 7.5625 \\
7. & Juli & 5 & 7.75 & -2.75 & 7.5625 \\
8. & Augs & 9 & 7.75 & 1.25 & 1.5625 \\
9. & Sept & 9 & 7.75 & 1.25 & 1.5625 \\
10. & Okt & 10 & 7.75 & 2.25 & 5.0625 \\
11. & Nov & 10 & 7.75 & 2.25 & 5.0625 \\
12. & Des & 10 & 7.75 & 2.25 & 5.0625 \\
& Jumlah & 93 & & & 66.249 \\
\hline
\end{tabular}

Sumber: Data Primer diolah, 2016 


$$
\begin{aligned}
& S D=\sqrt{\frac{\sum(X-X)^{2}}{n}} \\
& S D=\sqrt{\frac{66.2495}{12}} \\
& S D=\sqrt{55.207}=\sqrt{55} \\
& S D=7.416 \text { unit }
\end{aligned}
$$

\section{Titik Pemesanan Kembali}

\section{(Re Order Point)}

CV. Alfa Nafis memiliki waktu tunggu dalam pemesanan adalah selama hari atau bisa dikatakan lead time (L) 7 hari, dan dengan rata-rata jumlah karyawan selama 300 hari dalam setahun. Sebelum menghitung ROP maka dahulukan dicari tingkat pengunaan bahan baku per hari dengan cara sebagai berikut:

$$
\begin{aligned}
& \mathrm{d}=\frac{D}{t} \\
& d=\frac{7.75}{300}=0.2 \text { unit }
\end{aligned}
$$

Maka titik pemesanan kembali (ROP) adalah berikut:

DAFTAR PUSTAKA

Heizer, Jay dan Render Barry. 2008. Manajemen Operasi. Edisi 7. Jakarta : Salemba Empat. Kusuma, H. (2009). Manajemen Produksi. Yogyakarta : Andi Roger, 2000. Pengembilan Keputusan Dalam Suatu Fungsi Operasi, Edisi Ketiga. Erlangga: Jakarta.

$$
\begin{aligned}
\text { ROP } & =(d \times L)+S S \\
& =0.2 \times 7 \text { hari })+7.416 \text { unit } \\
& =8.546 \text { unit }
\end{aligned}
$$

Jadi perusahaan harus melakukan pemesanan bahan baku pada tingkat jumlah persediaan sebesar 8.546 unit.

\section{SIMPULAN DAN REKOMENDASI}

Berdasarkan hasil penelitian makan dapat disimpulkan bahwa CV. Alfa Nafis belum menerapkan metode Economy Order Quantity didalam pembelian atau pemesanan bahan baku. Metode EOQ dapat diterapkan pada CV. Alfa Nafis didalam pembelian bahan baku baja ringan. Hal ini dapat di buktikan dengan perhitungan EOQ perusahaan yang menyimpulkan bahwa pembelian bahan baku baja ringan yang ekonomis adalah 8.124 unit dengan frekuensi 4 kali pemesanan dalam satu tahun.

Syamsuddin, Lukman. 2011. Manajemen Keuangan Perusahaan: Konsep Aplikasi dalam Perencanaan, Pengawasan, dan Pengambilan Keputusan. Edisi Baru. Jakarta : PT. Raja Grafindo Persada.

Sofyan, Diana Khairani. 2013. Perencanaan dan Pengendalian Produksi. Yogyakarta : Graha IImu. 